\title{
Significados da Cirurgia Cardíaca para Pacientes Submetidos a Processo Cirúrgico
}

\author{
Shana Hastenpflug Wottrich \\ Universidade Federal do Pampa \\ Alberto Manuel Quintana \\ Universidade Federal de Santa Maria \\ Carmen Leontina Ojeda Ocampo Moré \\ Universidade Federal de Santa Catarina \\ Stefanie Griebeler Oliveira \\ Universidade Federal de Pelotas
}

\begin{abstract}
RESUMO
Este estudo teve por objetivo compreender os significados atribuídos à cirurgia cardíaca para pacientes submetidos a processo cirúrgico. Participaram 13 pacientes submetidos a cirurgia, sendo que os instrumentos de coleta de dados utilizados foram entrevistas semiestruturadas e a autofotografia. Os dados foram analisados qualitativamente com base na análise de conteúdo das narrativas, complementada pela análise das imagens, evidenciando que os significados atribuídos à cirurgia cardíaca giraram em torno da experiência cirúrgica como geradora de sofrimento, sentimentos de despersonalização e de desamparo, medo iminente de morte e estranhamento em relação ao corpo. Destaca-se a necessidade de reconhecimento dos significados atribuídos pelos pacientes ao processo cirúrgico, por parte dos profissionais de saúde que participam da atenção à saúde desses pacientes.
\end{abstract}

Palavras-chave: psicologia clínica da saúde; cirurgia; significado.

\begin{abstract}
Meanings of the cardiac surgery for patients who were submitted to the surgical process

This study aimed at understanding the meanings assigned to the cardiac surgery by patients who had undergone the surgical process. Thirteen patients submitted to surgery participated in the study and semi-structured interviews and auto-photography were used for data collection. Data was qualitatively analyzed, based on content analysis, together with image analysis, evidencing that meanings attributed to the cardiac surgery concerned the surgical experience as generating suffering, feelings of depersonalization and abandonment, imminent fear of death and strangeness concerning the body. We highlight the need for health professionals who are part of the health care team of such patients to recognize such meanings asigned by them to the surgical procedure.
\end{abstract}

Keywords: clinical health psychology, surgery, meaning.

A cirurgia cardíaca é considerada um procedimento invasivo, que tanto afeta aspectos fisiológicos do funcionamento do corpo, quanto repercute no âmbito psicológico, comportamental e social da vida dos sujeitos a ela submetidos. É concebida como um acontecimento limítrofe, pois pode preservar a vida ou extingui-la, sendo considerada assustadora, na medida em que envolve a geração de fantasias e medos (Oliveira \& Oliveira, 2010). O medo pode ser atribuído à cirurgia, à possibilidade de morte real, à anestesia, à antecipação da dor e à impossibilidade de controle da situação (Erdmann, Lanzoni, Callegaro, Baggio \& Koerich, 2013;
Oliveira \& Oliveira, 2010; Wottrich, Quintana, Camargo, Quadros \& Naujorks, 2013).

Estudos associados à temática evidenciam que o medo, ainda, pode estar associado ao desamparo diante da perda de controle vislumbrada na situação cirúrgica. Tal descontrole refere-se à circunstância de anestesia para a realização do procedimento, momento em que o sujeito entrega-se às mãos da equipe médica, o que inclui a perda de sentidos, e, por conseguinte, a perda da autonomia e do poder de decisão. A cirurgia é concebida, portanto, como uma experiência desorganizadora, causadora de sofrimento psíquico, posto que é geradora 
de sentimentos ambivalentes, angústia e aflição (D’Amato, 2008, Lanzoni, Higashi, Koerich, Erdmann, \& Baggio, 2015).

Nesse âmbito, torna-se relevante serem consideradas vivências presentes na internação hospitalar, situação que é pano de fundo para a cirurgia. Durante a hospitalização, há uma série de perdas, já que a rotina deixa de ser flexível e personalizada e o sujeito fica submisso a atividades e regras preestabelecidas. Diante disso, a despersonalização é uma das experiências possivelmente vivenciadas pelo paciente, caracterizando-se pela impossibilidade de o sujeito ser agente das decisões e ações de sua rotina. Somadas ao contexto descrito, frequentemente significado como hostil pelo paciente, a espera pela cirurgia e a impossibilidade de controlá-la podem acentuar a postura de passividade, gerando a sensação de frustração (Bergvik, Sørlie, \& Wynn, 2010; Botega, 2012; Wottrich et al., 2013).

A aceitação para a realização do procedimento é um processo que envolve sentimentos antagônicos nas vivências dos sujeitos. Por um lado, diante do contato do paciente com uma realidade até então desconhecida, há relatos de sentimentos de apreensão, medo, preocupação e ansiedade, gerando reações de tristeza e desespero (Bergvik et al., 2010, Lanzoni et al., 2015), que podem ser potencializadas em razão da incerteza da data em que a cirurgia será realizada (Banner, 2010; Banner, Miers, Clarke, \& Albarran, 2012; Lanzoni et al., 2015; Wottrich et al., 2013). Por outro lado, apresentam-se relatos de sentimentos positivos, tais como esperança (em relação à possibilidade de cura e reabilitação). A esperança, nesse escopo, diz respeito à perspectiva de uma nova vida, que contemple a ausência da dor, a capacidade de trabalho e o sentimento de utilidade e melhor qualidade de vida (Banner et al., 2012; Erdmann et al., 2013; Wottrich et al., 2013).

Independentemente das expectativas criadas em torno dos resultados do procedimento, em última instância, há incerteza sobre seus efeitos concretos. Considerando-se o momento da cirurgia em si, em que é realizada a incisão cirúrgica e o coração sofre as ações do cirurgião, o sucesso da cirurgia estaria associado a fatores extrínsecos ao sujeito, o que pode acarretar a acentuação de sentimentos de impotência nos pacientes (Ai, Peterson, Tice, Bolling, \& Koening, 2004). Dessa maneira, levando-se em conta a presença de sentimentos tão intensos, a adaptação psicológica à situação de cirurgia pode ter como determinante o acolhimento por parte dos profissionais que trabalham em contato direto com os pacientes. Nesse sentido, a quali- dade do atendimento da equipe hospitalar, no que diz respeito tanto à competência no desempenho das atribuições profissionais, quanto à construção de relacionamentos interpessoais consistentes com o paciente têm repercussões importantes no apoio emocional e na amenização da ansiedade decorrente do momento de tensão vivenciado (Lanzoni et al, 2015).

Ainda, sabendo que a experiência da cirurgia cardíaca diz respeito a um processo, que abarca as vivências dos momentos pré, trans e pós-cirúrgicos, cabe o questionamento sobre as implicações do procedimento, em termos de significados atribuídos à situação pós-cirúrgica, para os pacientes. Conforme refere Romano (2002), a incisão cirúrgica confere ao paciente um sta$t u s$, pois sua cicatriz representaria a marca de que é um sobrevivente do procedimento. Ao mesmo tempo, tal incisão pode representar a marca de que o corpo foi violado, de que a integridade do corpo do sujeito foi rompida (Banner, 2010), gerando vergonha (Lanzoni et al., 2015).

No período recente posterior à cirurgia cardíaca, as experiências descritas pelos pacientes como significativas são ligadas ao ambiente da unidade de recuperação pós-cirúrgica. É em tal ambiente que o paciente sai do sono anestésico e toma consciência de si mesmo e de sua situação, mantendo-se em estado alterado de consciência, amarrado ao leito, ligado a sondas, cateteres e drenos. Dessa forma, considerando esse um ambiente com sons, cheiros e ruídos incomuns, ele é descrito como assustador pelos sujeitos, na medida em que impõe condições nas quais o paciente se encontra mais debilitado e dependente, sentindo-se mais vulnerável (Erdmann et al, 2013, Lanzoni et al., 2015). Trata-se de um espaço, dentro do ambiente hospitalar, que pode ser concebido, metaforicamente, como uma ponte entre a vida e a morte, em que a tensão, a angústia e o estresse estão sempre presentes (Nieweglowski \& Moré, 2008).

Pesquisas realizadas apontam que alguns dos aspectos que mais incomodaram sujeitos submetidos a cirurgia cardíaca nesse período foram: a dor, nas costas, devido à posição de decúbito, e nos drenos; a restrição ao leito e a presença do tubo endotraqueal, devido à impossibilidade para comunicar-se; bem como a presença de sons e ruídos desconhecidos. Destaca-se, ainda, a menção, pelos pacientes, de nervosismo, ansiedade, medo e dor, causados pela presença do tubo endotraqueal, utilizado para que a respiração possa acontecer por meio artificial durante o efeito da anestesia (Dutra \& Coelho, 2008; Erdmann e cols., 2013; Lanzoni e cols., 2015, Linch, Guido, Pitthan, \& Lopes, 
2008).

No momento pós-operatório imediato, assim, a dor tem repercussão significativa no estado global do paciente, já que sua sensação dificulta a movimentação, evita a respiração adequada e interrompe o sono, fatores causadores de desgaste físico e com implicações na recuperação. Ainda, a menção da dor pode ser manifestação da carência e fragilidade do paciente em face da realidade, configurando-se, nesse âmbito, como um sintoma individual e subjetivo, cuja interpretação depende de aspectos sensitivos, emocionais e culturais (Dutra \& Coelho, 2008; Lanzoni et al, 2015; Linch et al, 2008).

Diante dessas considerações, constata-se que a vivência da recuperação na unidade de tratamento intensivo é permeada por uma ambivalência de sentimentos. Ao mesmo tempo em que essa experiência é compreendida como retorno à vida, a angústia de morte também está presente. Trata-se de um espaço em que o paciente está totalmente dependente da equipe de saúde, em que os cuidados oferecidos são redobrados e, marcados por urgência, gravidade e risco. Desde essa perspectiva, salienta-se que, ao mesmo tempo em que estar nesse local remete a sentimentos de impotência, também é nele que os cuidados são oferecidos de forma mais intensiva, remetendo à esperança de sucesso do tratamento e de restabelecimento da saúde e da vida (Senra \& Guimarães, 2010; Zaher, 2010).

Ainda, há importantes aspectos, em termos de alterações orgânicas, decorrentes do momento transoperatório, que repercutem nas implicações psicológicas no período pós-cirúrgico. Para a realização da maioria das cirurgias cardíacas é necessária a indução de uma parada cardiorrespiratória, utilizando-se a circulação extracorpórea, um sistema de propulsão e oxigenação do sangue que substitui temporariamente a função do pulmão e do coração (Senra \& Guimarães, 2010). Esse procedimento pode causar danos cerebrais devido à perfusão cerebral imprópria, bem como microembolização e hemorragia intracraniana (Ismael \& Almeida, 2008).

Assim, além do papel traumatizante da sala de recuperação devido à privação sensorial, alguns mecanismos bioquímicos da circulação extracorpórea, bem como a duração e a profundidade da hipotermia trazem consequências para a recuperação pós-cirúrgica. Tais consequências, mais comumente, referem-se a prejuízos cognitivos e da consciência e à consequente alteração de comportamento (Senra \& Guimarães, 2010; Silva \& Ribeiro, 2010). Nesse âmbito, possíveis alterações neurológicas pós-cirúrgicas traduzem-se em quei- xas sobre atividades nervosas superiores, fala, distúrbios da memória, concentração e atenção, coordenação visuo-motora, distúrbios visuais, insônia, depressão, distúrbios do comportamento e desorientação, entre outras. Além disso, a existência de alterações cognitivas após o procedimento estaria dependente do estágio e da duração da doença, efeito de drogas, idade do paciente e status socioeconômico (Ismael \& Almeida, 2008; Silva \& Ribeiro, 2010). Levando-se em conta tais apontamentos, para minimizar o efeito negativo dos sentimentos despertados pela situação cirúrgica, são importantes as orientações e os esclarecimentos realizados pela equipe no período pré-operatório, uma vez que podem contribuir para a diminuição dos níveis de ansiedade, que, quando excessiva, pode cooperar para o desencadeamento de alterações comportamentais após a cirurgia (Silva \& Ribeiro, 2010).

A série de acontecimentos relatados, eventos que fazem parte do processo da cirurgia cardíaca, remete à ideia de que se trata de uma experiência complexa, cujo sucesso depende de um conjunto de ações articuladas, tanto por parte do paciente e de seus acompanhantes, quanto da equipe de saúde que os atende. Entende-se que tais ações são intrinsecamente dependentes do significado que as referidas experiências adquirem para os sujeitos envolvidos no processo; significado aqui entendido como o "querer-dizer" do fenômeno para o sujeito, na sua perspectiva e entendimento, levando-se em conta aspectos biológicos, psicológicos, sociais e culturais (Turato, 2008). Assim, considera-se que, trazer à tona o conjunto de significados atribuídos às experiências oriundas do processo cirúrgico, por parte dos pacientes, pode oferecer reflexões para subsidiar tanto as políticas de humanização no contexto hospitalar como, principalmente, o reconhecimento desses significados pela equipe de saúde, visando ao maior protagonismo do paciente.

No marco das afirmações acima, este estudo teve por objetivo compreender os significados atribuídos à cirurgia cardíaca para pacientes submetidos ao processo cirúrgico, considerando o sentido e a interpretação atribuídos às experiências do período que antecede a cirurgia, da cirurgia em si e do período pós-cirúrgico imediato.

\section{MÉTODO}

\section{Participantes}

Os participantes da presente pesquisa foram 13 pacientes pós-cirúrgicos, 12 homens e uma mulher, com 
idades que variaram entre 46 e 74 anos, com até um ano de realização do procedimento. A opção por esse período se deu em função dos apontamentos da literatura, posto que esse é um período crítico, que diz respeito à adaptação pós-cirúrgica (Romano, 2001) e à retomada da rotina de vida (Koivunen, Isola, \& Lukkarinen, 2007). Foram excluídos da pesquisa pacientes menores de 18 anos, não residentes na cidade de realização do estudo e aqueles que, em função de disfunções físicas e orgânicas, não pudessem falar. O número de entrevistados seguiu o critério de saturação teórica dos dados, considerando um criterioso estudo prévio, que teve como objetivo metodológico estabelecer um número de entrevistas adequado ao contexto da pesquisa qualitativa, sendo 12 entrevistas o suficientes para se atingir a saturação teórica das categorias em resposta aos objetivos da pesquisa (Guest, Bunce, \& Johnson, 2006).

\section{Instrumentos e procedimentos}

A coleta de dados foi realizada com base na entrevista e na autofotografia. A modalidade de entrevista escolhida foi a semiestruturada, por permitir maior flexibilidade ao entrevistado, possibilitando, por conseguinte, seu retrato de experiências, concepções e atitudes (Turato, 2008). Assim, a entrevista não constou de perguntas pré-formuladas, mas de tópicos em que os participantes eram incentivados a falar sobre suas vivências. A autofotografia foi utilizada, de forma coadjuvante na coleta de dados, a fim de buscar atribuições de significados a imagens produzidas pelos próprios sujeitos. Pensou-se que o uso de tal recurso poderia facilitar a expressão dos participantes, pressupondo que isso, sem o uso da linguagem verbal, implicaria maior possibilidade de manifestação do self (Neiva-Silva \& Koller, 2002).

Os participantes da pesquisa foram contatados com base em consultas ambulatoriais em um hospital universitário do interior do Rio Grande do Sul. Após consulta com o médico da instituição específica, foram convidados pessoalmente pela pesquisadora a participarem do estudo. Inicialmente, mediante assinatura do Termo de Consentimento Livre e Esclarecido, foi realizada uma entrevista, na qual foram abarcados os seguintes eixos norteadores: o processo de preparação para a cirurgia, o paciente antes da cirurgia, as expectativas diante da cirurgia, a cirurgia e a recuperação.

Em seguida, foi exposto o convite para participarem de um segundo momento da pesquisa, que envolvia a autofotografia. Conforme sua disponibilidade e aceitação, os participantes receberam uma máquina fotográfica analógica a fim de produzirem 12 fotos em resposta à seguinte solicitação: "Será entregue a você uma máquina fotográfica com um filme de 12 poses. Gostaria que você produzisse imagens que retratassem, de alguma forma, as suas vivências pertinentes à cirurgia". Foi esclarecido, ainda, que tal máquina e as fotos pertenciam ao pesquisador, que entraria em contato, via ligação telefônica, conforme o combinado, para recuperar a máquina e revelar o filme. Caso aceitassem participar desse segundo momento, eram convidados a realizar uma segunda entrevista, que versaria sobre o conteúdo das fotos. Cabe ressaltar que, dos 13 pacientes participantes da pesquisa, oito concordaram em participar dessa segunda etapa da coleta dos dados. As entrevistas de todos foram gravadas, com o consentimento dos participantes, e, posteriormente, transcritas, para fins de análise.

O projeto de pesquisa que culminou neste trabalho foi realizado conforme as recomendações éticas da Resolução 196/96 do Conselho Nacional de Saúde, que normatiza as condições da pesquisa que envolve seres humanos, e aprovado no Comitê de Ética em Pesquisa da instituição em que foi realizada a coleta dos dados, sob o número CAAE 0174.0.243.000-09. Para preservar o sigilo e o anonimato dos participantes, eles serão identificados pelas letras $\mathrm{M}$ ou $\mathrm{F}$ (masculino ou feminino), seguidas de um número sequencial (que indica a ordem de realização das entrevistas), da idade e do tempo pós-operatório (P.O.).

\section{Análise dos dados}

Cabe ressaltar que as narrativas e as imagens foram analisadas de forma complementar (Joly, 2008), para possibilitar a emergência das categorias. A apreciação das entrevistas se deu por meio da análise de conteúdo proposta por Bardin (1977/2008) e Turato (2008). Seguiram-se, portanto, a leitura flutuante do material e sua posterior categorização, segundo critérios de relevância e repetição, tendo como foco o conteúdo latente nas narrativas (Turato, 2008). Assim como as entrevistas, as fotos também foram analisadas, de forma coadjuvante às narrativas que as acompanharam, oferecendo outros elementos para a produção de categorias, considerandose o roteiro proposto por Tacca (1991), que foi operacionalizado com base na análise dos elementos centrais das imagens, no ângulo da câmera e no enquadramento e profundidade de campo.

Em termos de conteúdo das imagens, para fins de análise, consideraram-se tanto a narrativa interna quanto a externa das imagens. Por narrativa, entende-se a organização intencional de dados apresentada dentro de uma imagem. A narrativa interna diz respeito à descri- 
ção dos elementos gerais que compõem a imagem, enquanto a narrativa externa responde a questões mais amplas, tais como: quem produziu a foto, por que e quando foi produzida (Banks, 2009).

Tanto com relação às narrativas, quanto com relação às imagens, para a construção das categorias, considerou-se a presença de intenções valorativas implícitas e explícitas dos sujeitos, que foram analisadas em dois tempos. Num primeiro momento, a produção narrativa e a fotográfica de cada um foram colocadas como eixo da análise, buscando a apropriação dos significados das imagens em conjunto com as narrativas, que acompanharam sua visualização, formando categorias baseadas na análise das produções de cada indivíduo separadamente. Em um segundo momento, buscou-se a horizontalização da análise, ou seja, a categorização considerando as produções dos demais participantes da pesquisa, com relação tanto às suas narrativas sobre as fotos, quanto às fotos propriamente ditas.

\section{RESULTADOS E DISCUSSÃO}

Em decorrência da análise dos dados, surgiram quatro categorias, cujos dados obtidos se integram, advindos tanto das entrevistas semiestruturadas, quanto das imagens produzidas pelos pacientes, bem como das narrativas oriundas das entrevistas sobre as imagens, descritas a seguir.

\section{Vivendo "no limite"}

Essa categoria refere-se à cirurgia como algo que se insere na vida de forma abrupta, tendo o significado de uma ação que, embora compreendida como a única alternativa possível para se manter vivo, carrega também o risco de morte. Tais significados aproximam-se dos inferidos em pesquisa conduzida por Hirani, Patterson e Newman (2008), que referem a compreensão dos pacientes de que o procedimento cirúrgico é o recurso definitivo de tratamento, mediante esgotamento dos demais meios, considerados apenas intermediários. Nesse sentido, a experiência é compreendida como limítrofe, conforme os relatos que seguem:

E [a médica] me mandou... disse: "Vamos ver como está", mas já me preparou, me preparou o espírito. [...] Aí ela pegou e me disse: "Olha, o senhor prepare o seu espírito, que, de tantos remendos, tem um momento que não dá mais pra fazer remendos. Já fazer uma ponte e trocar as coronárias" (M1, 67 anos, P.O. 7 meses).

Até foi quando aconteceu, meu deu... Mas, o pessoal ficou assim, claro, apreensivo, fazer o quê? Era um negócio que tinha que fazer. Tava decretado que a angioplastia não dava. Tinha que cortar mesmo. (M2, 49 anos, P.O. 1 ano).
O caráter limítrofe da cirurgia aparece também com relação à sua significação dicotômica, entre a vida e a morte. Por um lado, o procedimento implica a esperança de uma vida nova, mas, por outro, pode significar a ameaça da perda da vida (Garbossa, Maldamer, Mortari, Biasi, \& Leguisamo, 2009; Oliveira \& Oliveira, 2010; Wottrich et al., 2013).

E daí foi quando o doutor disse: "Vou te encaminhar pro hospital universitário pra cirurgia. Marcar, porque daí a pouco mais tu vai ter que fazer a cirurgia. [...] Se não tu vai apagar" (M3, 46 anos, P.O. 10 meses).

Mas aí era bastante coronária que tava estragado e o médico disse que se não fosse a operação, nada feito. Que eu tava arriscando uma hora pra outra cair e não ter mais recurso (M4, 72 anos, P.O. 2 meses).

Nesse ínterim, cabe ressaltar o montante de sofrimento psíquico presente, já que o procedimento parece implicar um cenário em que imperam sentimentos ambivalentes e angustiantes (D'Amato, 2008; Lanzoni et $a l .$, 2015). Nota-se que falar sobre o procedimento despertou reações que remeteram à ansiedade vivenciada ao longo do evento, a qual, por sua vez, pareceu significar, em última instância, a possibilidade de finitude da vida.

Em síntese, constata-se que a cirurgia tem o significado de uma experiência que se insere abruptamente na vida dos sujeitos, causando um impacto emocional significativo, na medida em que representa, ao mesmo tempo, a possibilidade de continuação da vida e o risco de morte.

\section{A hospitalização e suas implicações}

A necessidade de submissão ao procedimento cirúrgico pressupõe a internação hospitalar, o que acaba por gerar uma série de implicações imbricadas nas vivências do tratamento. Entre elas, destaca-se a despersonalização, processo que remete o sujeito a uma posição passiva, colocando-o numa perspectiva existencial de assujeitado aos procedimentos e tratamentos médicos (Botega, 2012).

[...] a médica não me deixou sair da cama por causa do problema da cardiopatia. Aí tu, tu te sente assim meio ruim, porque eu não conseguia evacuar nada na maca. Aí, chegou um dia que eu consegui, que eu não aguentei e disse: "Doutora, pelo amor de Deus, deixa eu ir no banheiro, porque senão...". (M5, 50 anos, P.O. 10 meses).

Destaca-se, nesse escopo, a menção de uma posição de mal-estar, na medida em que os indivíduos não podem manter seu papel social como responsáveis por seus corpos e suas vidas diante da hospitalização, havendo limitações em relação à sua independência e à consequente experiência simbólica de morte social 
(Botega, 2012; D’Amato, 2008). Ainda, é importante destacar que o simples fato de estar no espaço hospitalar pode remeter à condição de impotência gerada pela doença.

[...] que o hospital liga a doença. Ele é ligado na doença: doença-hospital, né? (M1, 67 anos, P.O. 7 meses).

Nesse sentido, o significado atribuído ao hospital pode ser contraposto ao significado atribuído ao ambiente doméstico. Enquanto um espaço remete ao aprisionamento e à doença, o outro pode remeter à liberdade $\mathrm{e}$ à saúde (Quintana, Wottrich, Camargo, Cherer, \& Ries, 2011). A relevância do espaço hospitalar fica evidente, também, por meio das fotos do espaço, produzidas pelos participantes M1, M5, M6 e M8.

Para ilustrar o significado atribuído ao contexto hospitalar pelos participantes referidos, a figura 1 , produzida por M6, 57 anos, P.O. 10 meses, retrata um espaço que remete à situação de desconforto vivenciada pelo paciente durante a internação. Ao ser solicitado a descrever a imagem, o participante referiu a narrativa que segue.

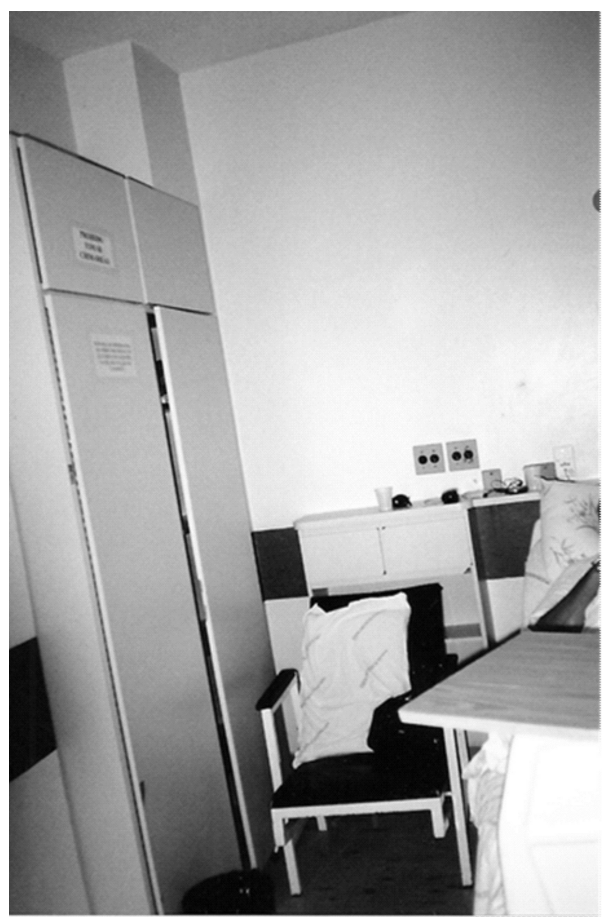

Figura 1. Produção fotográfica de M6, 57 anos, P.O. 10 meses.
Ah, essa aqui, doutora, essa aqui é a cadeirinha quando eu tava lá com muita dor. [...] ...essa cadeira aqui eu dormia sentado, quando tinha muita dor. Eu tava cansado de ficar, eu tava todo doído já. E essa cadeira era o alívio pra mim da cama, era o alívio da cama. Quando eu tava internado, eu fiquei 32 dias, doutora. Então, eu me sentia assim muito, com muita, muito, quando ia pra cadeira assim, que alívio, que coisa bem boa. Que coisa bem boa assim, e a cama me judiou muito... (M6, 57 anos, P.O. 10 meses).

Pode-se notar que a angulação da câmera retrata a cadeira de forma descendente, criando uma relação específica com o objeto (Tacca, 1991). Pode ser compreendida como uma relação de superioridade do participante com relação ao referente fotografado. Assim, retratar o objeto sob tal perspectiva pode ser entendido como um movimento em que o participante atualiza seu senso de domínio a respeito de sua vida. Metaforicamente, pode-se pensar que, no passado, ele teria sido dominado pelo espaço retratado na imagem, enquanto, hoje, é ele que o domina, na medida em que já passou pela situação e a revisita por intermédio da produção das imagens. Além disso, evidencia-se, pela narrativa que acompanha a imagem, uma perspectiva ambivalente do espaço hospitalar, tendo em vista que esse espaço significa alívio, ao mesmo tempo em que remete ao sofrimento.

Salienta-se, portanto, que o mal-estar diante da cirurgia não se instala apenas em função do procedimento em si, mas também em decorrência dos significados atribuídos ao contexto hospitalar. Mediante a necessidade de manutenção de uma postura dependente das rotinas e procedimentos estabelecidos institucionalmente, os participantes acabam por perder referenciais das suas possibilidades como sujeitos autônomos, o que acentua o sofrimento oriundo da experiência cirúrgica, foco da categoria descrita a seguir.

\section{Cirurgia: o descontrole e a iminência da morte}

Nessa categoria, destaca-se a sensação de impotência mediante a perda de controle consequente da indução anestésica para a realização do procedimento cirúrgico, pois o sujeito precisa entregar-se nas mãos da equipe. Seu sucesso ou fracasso, sob essa perspectiva, depende de fatores extrínsecos aos sujeitos (Ai et al., 2004).

A relevância do contexto em que ocorreram os procedimentos invasivos, para os participantes da pesquisa, apresenta-se no investimento de esforço dos sujeitos para tirarem as fotos, já que buscaram permissão administrativa para retratar os locais em que foram realizados os procedimentos. Alguns espaços são retratados por meio das fotografias produzidas por M1, M6 e M8. Um exemplo, produzido por M1, 67 anos, P.O. 7 me- 
ses, encontra-se na figura 2. A imagem registra a sala em que o paciente realizou uma angioplastia. A mesa em que foi realizado o procedimento ocupa o centro da imagem, e, portanto, recebe uma carga valorativa do participante (Tacca, 1991).

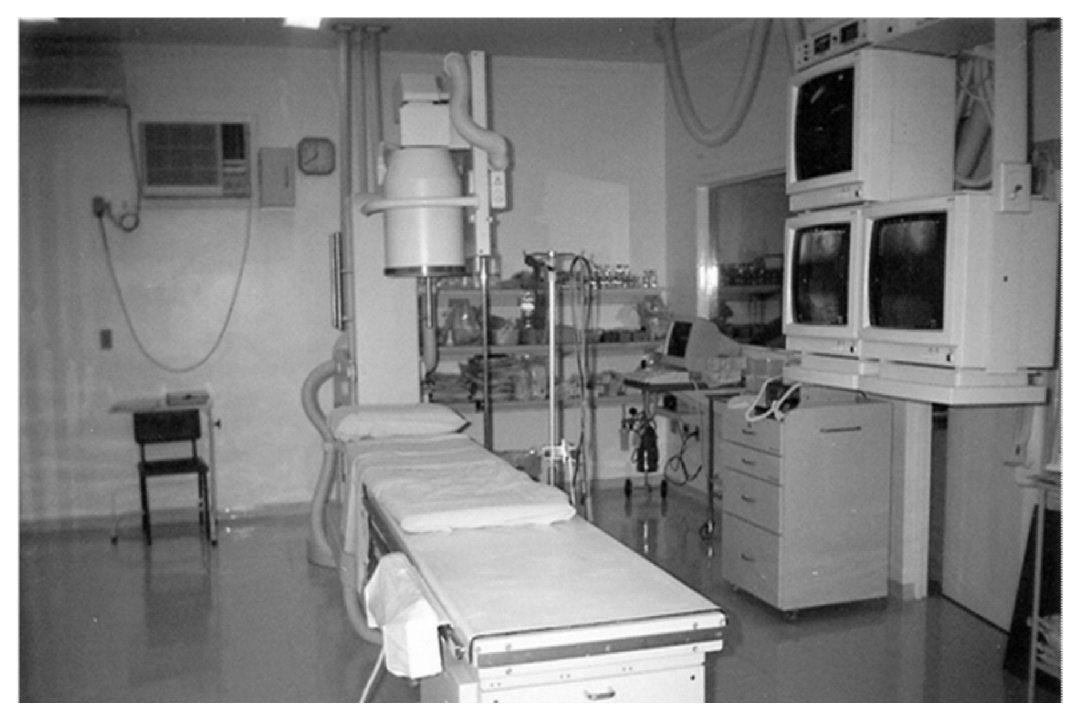

Figura 2. Produção fotográfica de M1, 67 anos, P.O. 7 meses.

Ressalta-se, dessa forma, que os procedimentos vivenciados pelos participantes significam, para eles, momentos direcionados pela equipe, em que os pacientes não são autônomos ou ativos em termos decisórios (Wottrich, Quintana, Camargo, \& Beck, 2015) conforme evidenciam as narrativas a seguir:

Cheguei lá, me botaram numa mesa, abriram os meus braços, já veio um me depilando e foram se apresentando. Aí, de repente eu apaguei, não vi nada. (M3, 46 anos, P.O. 10 meses).

Tu não vê nada! Tu só vê quando te levam pra lá. Mais nada (M7, 62 anos, P.O. 1 ano).

Nesse âmbito, pode-se pensar na anestesia como uma espécie de morte temporária, já que o processo implica a perda dos sentidos para a realização do procedimento, podendo trazer mais angústia do que a operação em si (Oliveira \& Oliveira, 2010). Tal representação é ilustrada nas narrativas que seguem.

Quando eu vim pra fazer a cirurgia, eu achei que não ia voltar (F1, 51 anos, P.O. 3 meses).

Que tu sabe que eles param o coração da gente lá na cirurgia e eles põem numa máquina, e a máquina fica tocando. A gente fica numa sobrevida ali. Fica numa sobrevida, coisa e tal, e o coração parado (M1, 67 anos, P.O. 7 meses).

A última narrativa destaca aspectos que remetem a uma condição intermitente, entre a vida e a morte. Considerando-se que o coração é culturalmente reconhecido como a sede da vida, das emoções e do caráter do indi- víduo, é possível pensar nas repercussões de um procedimento que implica parada temporária de seu funcionamento, com o uso da circulação extra-corpórea (Ismael \& Almeida, 2008; Oliveira \& Oliveira, 2010; Romano, 2002).

Concordando com a importância desse espaço, salienta-se uma imagem ilustrativa produzida por um dos sujeitos (M8, 49 anos, P.O. 5 meses) (figura 3). A imagem retrata o corredor para a sala de cirurgia, de forma que o enquadramento e a profundidade de campo remetem ao espaço do corredor até a sala cirúrgica, aludindo a um caminho, a um processo que culmina com o procedimento cirúrgico.

Os pacientes também mencionam a utilização do tubo endotraqueal como algo da ordem da violação do seu corpo, algo cuja antecipação implica em ansiedade (Moro, Godoy, Goulart, Muniz, \& Modolo, 2009). Ao visualizar a figura 3 , que remete à sala onde foi realizada a cirurgia, M8 verbalizou a seguinte narrativa descritiva de quando passou pela experiência do procedimento:

Eu pedi uma coisa pras enfermeiras: minhas conhecidas, né? Eu disse assim pra elas: "Depois da operação, vocês não deixem eu com isso aí na boca". Aquele aparelho, sabe? Que bota na boca, não sei como é o nome daquilo, um tubo. (M8, 49 anos, P.O. 5 meses).

Assim, ao mesmo tempo em que os pacientes pare- 
cem ter dificuldades de entregarem-se nas mãos da equipe para que o procedimento ocorra, também aparece o desejo de que não estejam acordados para depararem com a dor e o sentimento de impotência oriundo da impossibilidade de controlar o próprio corpo (Oliveira \& Oliveira, 2010). Dessa forma, os significados atribuídos pelos participantes, nessa categoria, referem-se, em síntese, a sentimentos de desapropriação do próprio corpo e da própria vida, geradores da sensação de impotência e frustração.

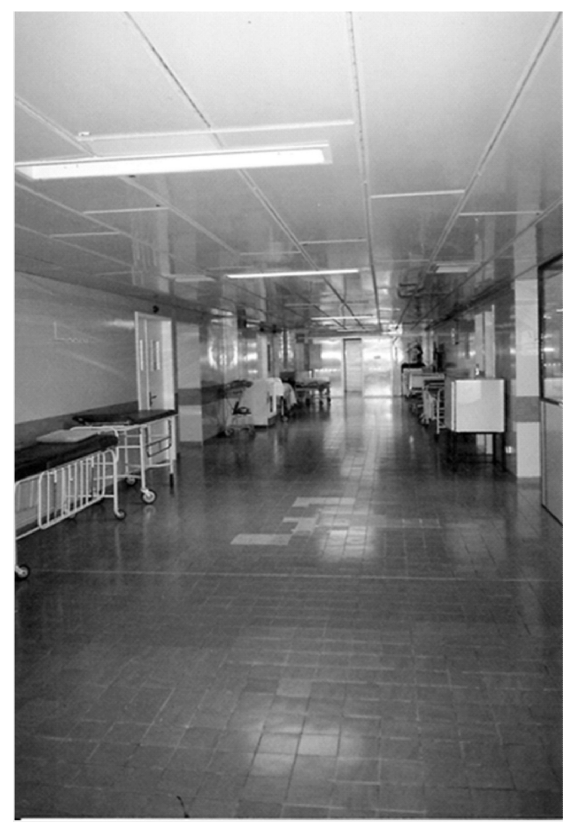

Figura 3. Produção fotográfica de M8, 49 anos, P.O. 5 meses.

\section{Acordar da cirurgia: "estranhamento" e violação do corpo}

O despertar do sono anestésico parece causar uma sensação de estranhamento nos sujeitos, na medida em que relatam certo desconhecimento do corpo na situação em que ele se encontra. $\mathrm{O}$ ambiente da unidade pós-operatória parece acentuar tal estranhamento, causando desorganização psíquica. Os pacientes deparam com cheiros e sons incomuns (Erdmann et al., 2013, Lanzoni et al., 2015). Essas impressões são exemplificadas nas narrativas a seguir:

\footnotetext{
Ah, é... quando acordou, aí é cruel. A gente se acorda todo errado. Tu se olha, tudo inchado assim. Aí, quando me acordei, já tinham me tirado o treco que tinha na boca. Aí, só eles me pegaram assim, eu vomitei, sei lá, uma coisa assim, sabe. Um troço nojento. (M2, 49 anos, P.O. 1 ano).

É, aquele negócio. Depois eles tiram. Então é uma manguinha aqui, tirando um líquido daqui e outra aqui [aponta para o local onde provavelmente foram colocados os drenos]. É cheio de
}

coisa. Então, eu acordei, me acordei, me lembro como se fosse hoje assim [olha para todos os lados, silêncio]. Estranhei o lugar. Fiquei olhando, assim, meio abismado. Olhei pra mim. De certo, ele já me fez a cirurgia. Mas será que eles já fizeram? [fala baixinho]. (M7, 62 anos, P.O. 1 ano).

Salientam-se ainda, no relato desse cenário pelos sujeitos, significados que remetem à concepção do corpo como extensão das máquinas e aparelhos que o mantêm funcionando, o que pode colaborar para um questionamento do sujeito sobre a propriedade do próprio corpo, ou seja, indagações sobre quem ou o quê exerce poder sobre aquele novo corpo, diferentemente do que existia antes do procedimento. O depoimento que segue ilustra tal sensação de desapropriação:

Eu me lembro que eu me acordei e tava tudo... Eu me lembro que eu me acordei e não podia mexer a perna, endureceu tudo. Eu até me apavorei (M9, 65 anos, P.O. 1 mês).

Nesse contexto, destacam-se, portanto, os relatos de sentimentos de descontrole e desamparo, que podem culminar no aumento da vulnerabilidade sentida pelos pacientes (Linch et al., 2008; Lanzoni et al., 2015; Senra \& Guimarães, 2010). Os dados dessa categoria referem que os pacientes sentem que a autonomia sobre o próprio corpo é limitada e que desconhecem a si mesmos após o procedimento, remetendo, em última instância, à significação da cirurgia como prova da impotência e da finitude humanas.

\section{CONSIDERAÇÕES FINAIS}

Os resultados desta pesquisa evidenciam a experiência cirúrgica como geradora de uma série de repercussões, que abarcam a compreensão dos participantes sobre si mesmos. Tais repercussões dizem respeito aos significados atribuídos ao coração em âmbito cultural e individual, pois mexer nesse órgão parece não significar apenas mexer na concretude da morfologia e fisiologia que ele comporta, mas também em aspectos simbólicos. Nesse sentido, os resultados chamam a atenção para o impacto que a cirurgia tem em termos de sofrimento psíquico, remetendo a um significativo sentimento de desamparo, mediante a perda de referenciais em relação ao próprio corpo e às suas capacidades, gerada pela experiência.

Cabe ressaltar, no entanto, que este estudo trabalhou com um recorte específico do período pós-cirúrgico, a saber, a delimitação de um ano após o procedimento. Considera-se pertinente aprofundar estudos que busquem compreender os significados atribuídos à cirurgia num período posterior a esse, com vistas a pesquisar possíveis ressignificações da experiência diante de vivências de reabilitação que tomam um período de tem- 
po mais extenso.

Por sua vez, entende-se que, diante dos significados atribuídos pelos participantes, é necessário implementar e/ou desenvolver uma postura que considere um olhar integral por parte dos profissionais que participam do processo de atenção à saúde desses pacientes. Cumpre salientar a demanda de reflexão, em termos institucionais, sobre políticas e estratégias de saúde que concebam o cuidado na perspectiva da complexidade dos aspectos envolvidos no adoecimento e no tratamento das cardiopatias. Especialmente em relação à preparação dos pacientes que são submetidos ao processo cirúrgico, tais reflexões deverão apontar em direção à construção do protagonismo dos usuários do sistema de saúde em relação ao seu tratamento, no sentido do reconhecimento das suas necessidades, para além dos aspectos biológicos.

\section{REFERÊNCIAS}

Ai, A. L., Peterson, C., Tice, T. N., Bolling, S.F., \& Koening, H. G. (2004). Faith-based and secular pathways to hope and optimistic subconstructs in middle-aged and older cardiac patients. Journal of Health Psychology, 9, 435-450.

Banks, M. (2009). Dados visuais para pesquisa qualitativa. Porto Alegre: Artmed.

Banner, D. (2010). Becoming a coronary artery bypass graft surgery patient: a grounded theory study of women's experiences. Journal of Clinical Nursing, 19, 3123-3133.

Banner, D., Miers, M., Clarke, B., \& Albarran, J. (2012). Women's experiences of undergoing coronary artery bypass graft surgery. Journal of Advanced Nursing, 68(4), 919-930.

Bardin, L. (2008). Análise de Conteúdo (L. A. Reto \& A. Pinheiro, Trad.). Lisboa: Ed. 70. (Original publicado em 1977)

Bergvik, S., Sørlie, T., \& Wynn, R. (2010). Approach and avoidance coping and regulatory focus in patients having coronary artery bypass surgery. Journal of Health Psychology, 15, 915-924.

Botega, N. J. (2012). Reação à doença e à hospitalização. Em N. J. Botega (Órg.), Prática psiquiátrica no hospital geral: Interconsulta e emergência ( $3^{\mathrm{a}}$ ed.). (pp. 49-66). Porto Alegre: Artmed.

D'Amato, C. V. S. (2008). Mortes, perdas e luto em cardiologia. Em C. P. Almeida \& A. L. A. Ribeiro (Orgs.), Psicologia em cardiologia: Novas tendências (pp. 199-208). Campinas, SP: Alínea.

Dutra, C. M. P., \& Coelho, M. J. (2008). O tempo de cicatrização do coração: cuidar e os cuidados do cliente para superar as dificuldades após cirurgia cardíaca. Enfermería Global, 12, 1-7.

Erdmann, A. L., Lanzoni, G. M. M., Callegaro, G. D., Baggio, M. A., \& Koerich, C. (2013). Compreendendo o processo de viver significado por pacientes submetidos a cirurgia de revascularização do mio- cárdio. Revista Latino-Americana de Enfermagem, 21(1), 8 telas.

Garbossa, A., Maldamer, E., Mortari, D. M., Biasi, J., \& Leguisamo, C. P. (2009). Efeitos de orientações fisioterapêuticas sobre a ansiedade de pacientes submetidos à cirurgia de revascularização miocárdica. Revista Brasileira de Cirurgia Cardiovascular, 24, 359-366.

Guest, G., Bunce, A., \& Johnson, L. (2006). How many interviews are enough?: An experiment with data saturation and variability. Field Methods, 18, 59-82.

Hirani, S. P., Patterson, D. L. H., \& Newman, S. P. (2008). What do coronary artery disease patients think about their treatments? An assessment of patients' treatment representations. Journal of Health Psychology, 13, 311-322.

Ismael, S. M. C., \& Almeida, C. P. (2008). Possíveis alterações neuropsicológicas em pacientes submetidos à cirurgia cardíaca. Em C. P. Almeida \& A. L. A. Ribeiro (Orgs.), Psicologia em cardiologia: Novas tendências (pp. 55-74). Campinas, SP: Alinea.

Joly, M. (2008). Introdução à análise da imagem. (12 ed.). Campinas, SP: Papirus.

Koivunen, K., Isola, A., \& Lukkarinen, H. (2007). Rehabilitation and guidance as reported by women and men who had undergone coronary bypass surgery. Journal of Cardiovascular Nursing, 16, 688697.

Lanzoni, G. M. M., Higashi, G. D. C., Koerich, C., Erdmann, A. L., \& Baggio, M. A. (2015). Fatores que influenciam o processo de viver a revascularização miocárdica. Texto \& Contexto Enfermagem, 24(1), 270-278.

Linch, G. F. C., Guido, L. A., Pitthan, L. O., \& Lopes, L. F. D. (2008). Estressores identificados por pacientes submetidos à revascularização do miocárdio e angioplastia coronária transluminal percutânea - estudo quantitativo. Online Brazilian Journal of Nursing, 7. Retirado em 1 de Abril de 2012, de http://www.objnursing.uff.br/index. php/nursing/article/view/j.1676-4285.2008.1432/371

Moro, E. T., Godoy, R. C. S., Goulart, A. P., Muniz, L., \& Modolo, N. S. P. (2009). Principais preocupações dos pacientes sobre as complicações mais frequentes na sala de recuperação pós-anestésica. Revista Brasileira de Anestesiologia, 59, 716-724.

Neiva-Silva, L., \& Koller, S. H. (2002). O uso da fotografia em psicologia. Estudos de Psicologia, 7, 237 250 .

Nieweglowski, V. H., \& Moré, C. L. O. O. (2008). Comunicação equipe-família em unidade de terapia intensiva pediátrica: impacto no processo de hospitalização. Estudos de Psicologia, 25, 111-122.

Oliveira, S.A., \& Oliveira, M. F. P. (2010). Psicologia e cardiologia: Um desafio que deu certo. Em A.L.A. Ribeiro \& M. L. Gagliani (Orgs.), Psicologia e cardiologia: Um desafio que deu certo (pp.1-5). São Paulo: Editora Atheneu.

Quintana, A. M., Wottrich, S. H., Camargo, V. P., Cherer, E. Q., \& Ries, P. K. (2011). Lutos e lutas: reestruturações familiares diante do câncer em uma 
criança/adolescente. Psicologia Argumento, 29, 143154

Romano, B. W. (2001). Aspectos psicológicos e sua importância na cirurgia das coronárias. Em B. W. Romano (Org.), Psicologia e cardiologia: Encontros possiveis (pp. 111-144). São Paulo: Casa do Psicólogo.

Romano, B. W. (2002). Por que considerar os aspectos psicológicos na cirurgia de revascularização do miocárdio. Em E. W. B. Romano (Org.), A prática da psicologia nos hospitais (pp.55-66). São Paulo: Pioneira Thomson Learning.

Senra, D. F., \& Guimarães, C. P. A. (2010). UTI de cirurgia cardíaca. Em A.L.A. Ribeiro \& M. L. Gagliani (Orgs.), Psicologia e cardiologia: Um desafio que deu certo (pp.113-120). São Paulo: Editora Atheneu.

Silva, I. F., \& Ribeiro, A. L. A. (2010). Anestesia em cirurgia cardíaca: Alterações de comportamento no pós-operatório. Em A.L.A. Ribeiro \& M. L. Gagliani (Orgs.), Psicologia e cardiologia: Um desafio que deu certo (pp.67-76). São Paulo: Editora Atheneu.

Tacca, F. (1991). Sapateiro: o retrato da casa. Revista Studium 10. Retirado em 22 de Junho de 2009, de http://www.studium.iar.unicamp.br/10/4.html.
Turato, E. R. (2008). Tratado da metodologia da pesquisa clínico-qualitativa. Petrópolis: Vozes.

Wottrich, S. H., Quintana, A. M., Camargo, V. P., \& Beck, C. L. C. (2015). "Manifestos do coração": significados atribuídos à doença por pacientes cardíacos pré-cirúrgicos. Psicologia: Teoria e Pesquisa, 31(2), 213-219.

Wottrich, S. H., Quintana, A. M., Camargo, V. P., Quadros, C. O. P., \& Naujorks, A. A. (2013). Significados e vivências mediante a indicação cirúrgica para pacientes cardíacos. Psicologia em Estudo, 18(4), 609-619.

Zaher, V. L. (2010). Questões éticas dentro de uma unidade de terapia intensiva cardiológica. Em A.L.A. Ribeiro \& M. L. Gagliani (Orgs.), Psicologia e cardiologia: Um desafio que deu certo (pp.175-183). São Paulo: Editora Atheneu.

Recebido em: 07/10/2012 Primeira decisão editorial em: 24/09/2015 Aceito em: 12/01/2016 